\title{
Residential electricity demand in Spain: new empirical evidence using aggregate data
}

\author{
Leticia Blázquez ${ }^{\mathrm{a}}$, Nina Boogen ${ }^{\mathrm{b}}$ and Massimo Filippini ${ }^{\mathrm{b}, \mathrm{c}}$ \\ ${ }^{a}$ Department of Spanish and International Economics, Econometrics and Economic History and \\ Institutions, Toledo Faculty of Law and Social Sciences, University of Castilla-La Mancha, \\ Cobertizo de San Pedro Mártir, s/n, 45071, Toledo, Spain. Phone number: (34)925268800-Ext \\ 5163, Fax number (34)925 26880. Leticia.Blazquez@uclm.es. (Corresponding Author). \\ b CEPE-Centre for Energy Policy and Economics, Federal Institute of Technology, \\ Zürichbergstrasse 18(ZUE E) CH-8032, Zurich, Switzerland. nboogen@ethz.ch. \\ c Department of Economics, Università della Svizzera Italiana, Via Giuseppe Buffi 13CH-690 \\ Lugano, Switzerland. Massimo.filippini@usi.ch.
}

Version: November, 2012

\begin{abstract}
This paper presents an empirical analysis on residential demand for electricity. This analysis has been performed using aggregate panel data at the province level for 47 Spanish provinces for the period from 2000 to 2008. For this purpose, we estimated a log-log demand equation for electricity consumption using a dynamic partial adjustment approach. This dynamic demand function has been estimated using a two-step system GMM estimator proposed by Blundell and Bond (1998). The purpose of this empirical analysis is to highlight some of the characteristics of Spanish residential electricity demand. Particular attention has been paid to the influence of price, income, and weather conditions on electricity demand. The estimated short and long-run own price elasticities are negative, as expected, but lower than 1. Furthermore, weather variables have a significant impact on electricity demand.
\end{abstract}

JEL: D, D2, Q, Q4, R2.

Keywords: residential electricity demand, panel data, partial adjustment model, aggregate data. 


\section{Residential electricity demand in Spain: new empirical evidence using aggregate data}

\section{Introduction}

The study of Spanish domestic energy demand is especially appealing for several reasons. Since the early nineties, Spain has experimented profound social, economic, cultural and demographic changes; changes which have accelerated in the last decade. These social and economic transformations have significantly conditioned the determinants of residential energy demand. As an illustration, from 1990 to 2008, Spanish residential final energy demand grew 73\%, with an annual growth rate four times higher than those observed in other European countries. And in the particular case of electricity, Spanish residential electricity demand increased by $32 \%$ from 2000 to 2008 , becoming the largest and most dynamic electricity consumption sector. This growth has been one of the highest among European countries. Specifically, the main reasons for this trend have been (i) a significant population increase and an even larger increase in the number of new houses and apartments; (ii) a decreasing household size as a consequence of changes in the structure and composition of households; (iii) a convergence with the rest of Europe in household equipment as a result of more similar habits and behaviours; and (iv) a long lasting policy of low tariffs.

Together with economic and social variables, Spanish electricity demand is related to climatic factors. For example, these climatic factors can be summarized by the temperatures registered in different locations. Spain is a very suitable setting to examine the impact of weather conditions on electricity demand because the country is far from being a homogenous meteorological territory. In a simple approximation, six separate climate zones can be differentiated.

The significant growth in electricity consumption Spain has experienced in recent decades has increased the $\mathrm{CO}_{2}$ emissions levels in the country, making environmental and supply security problems more severe, as a considerable portion (32\%) of the electricity consumed in Spain is produced in coal and gas power plants. These concerns have made the encouragement of efficient electricity use by residential consumers a main objective of Spanish energy policy. ${ }^{1}$

In order to design policy instruments that influence electricity demand, it is crucial to have information on price and income elasticities and to identify the determinants of this demand; i.e. to estimate Spanish residential electricity demand using an econometric approach. 
Since the pioneer work of Houthakker (1951), vast literature on modelling the residential demand for electricity and examining its determinants has been published. Donatos and Mergos (1991); Burney (1995); Silk and Joutz (1997); Filippini (1999); Lariviere and Lafrance (1999); Christian and Michael (2000); García-Cerruti (2000); Miller (2002); Lin (2003); Holtedahl and Joutz (2004), Hondroyiannis (2004); Narayan et al. (2007); Mohammadi (2009) and Alberini and Filippini (2011) are some of the most recent studies. Most of these works have estimated both the short-run and the longrun residential demand for electricity using aggregate data and applying different methodologies. The differentiation between short and long-run is essential to analyse the electricity demand since their determinants are different. Electricity is used in combination with electrical appliances to produce energy services such as lighting, cooking and heating. And while in the short-run the demand variation should be related to a higher or lower intensity use of current equipment (due to meteorological changes, for instance), in the medium and long term, the change of the types of electrical appliances used as well as changes in behaviour have an impact on electricity demand (Moral-Carcedo and Vicéns-Otero, 2005). The price and income elasticity values reported in the literature are fairly heterogeneous. The heterogeneity of the results could be due to differences in the period and region considered in the analysis and to the econometric approach used for the estimation.

Despite this extensive literature, there are few studies focusing on the demand for residential electricity in Spain. Two main contributions are Labandeira et al. (2006) and Labandeira et al. (2011). Both works analyse Spanish residential demand using household disaggregate data. The first paper estimates a residential energy demand system using data from a national statistical survey for the period between 1975-1995. They apply an extension of Deaton and Muellbauer's (1980) Almost Ideal Demand Model, and consider the following energy sources: electricity, natural gas, LPG (butane and propane gases) and car fuels. They found a price elasticity value of -0.80 and an income elasticity value of 0.7. In comparison to the aforementioned literature, these values are relatively high. The second work focuses on the estimation of Spanish industrial and residential electricity demand using monthly data from 2005 to 2007 from one of the largest electric companies. The authors consider electricity and gas prices as well as some socioeconomic and climate factors to be explanatory variables. From an econometric point of view, a random effects model for panel data is used. The study reports a short-run electricity price elasticity of -0.25 .

Due to the scarce attention paid so far in this field to the specific case of the Spanish economy and the disparate results obtained in the two main papers, it seems clear that further research must be carried out. 
The objectives of this paper are the following: (i) provide new empirical evidence for Spanish residential electricity demand on the values of the short and long-run price and income elasticities; (ii) analyse the impact of climate on electricity demand using different definitions for the computation of the climate variables.

In contrast to the previous papers on Spain, this analysis will be performed using aggregate panel data for 47 Spanish provinces from 2000 to 2008. For this purpose, we estimated a demand equation for electricity consumption using a dynamic partial adjustment approach. This dynamic demand function will be estimated using the two-step GMM estimator proposed by Blundell-Bond (1998). Therefore, this paper contributes to the literature on Spanish residential electricity demand by providing an analysis that considers the whole national territory, covers a wider and more recent period of time than previous analysis, uses aggregate data, and applies a dynamic econometric approach.

The paper is organized as follows: Section 2 provides a description of the domestic Spanish sector from an energy perspective. Section 3 presents the empirical model. In section 4, data used in the analysis and the calculation of the weather variables are discussed, while section 5 offers the econometric approaches and the empirical results applied. Some concluding remarks appear in section 6 of the paper.

\section{Spanish Residential Energy Demand}

Spanish families represent a much lower percentage of the aggregate final energy consumption than in the EU: $16.4 \%$ versus $25.4 \%$ in 2008 . The milder Spanish climate is the key factor in determining this difference. Although heating is the most relevant destination of energy in both areas, its participation in the energy consumption of Spanish households is much lower than the EU average: 47\% versus $70 \%$ (Graph 1). Excluding heating, a growing participation of air conditioning, lighting and hot water is observed in the last decade in contrast to the decreasing relative importance of energy consumption from appliances and cookers.

In connection with the dissimilar energy consumption destinations, while gas is the prominent energy source in the EU (39\%), Spanish families consume primarily electricity (39\%). The high share of electricity consumption in Spain is due to the inferior utilization of heating in Spain together with the high proportion of houses that still do not have any kind of heating system installed. These houses frequently utilize radiators or other auxiliary electrical heating systems. Despite these differences, a common trend is detected in both the EU and Spain: the decreasing relative importance of solid fuels and oil products in favour of natural gas and electricity. 
Graph 1. Final energy consumption in Spanish households by fuel and use (Ktep) (2009)

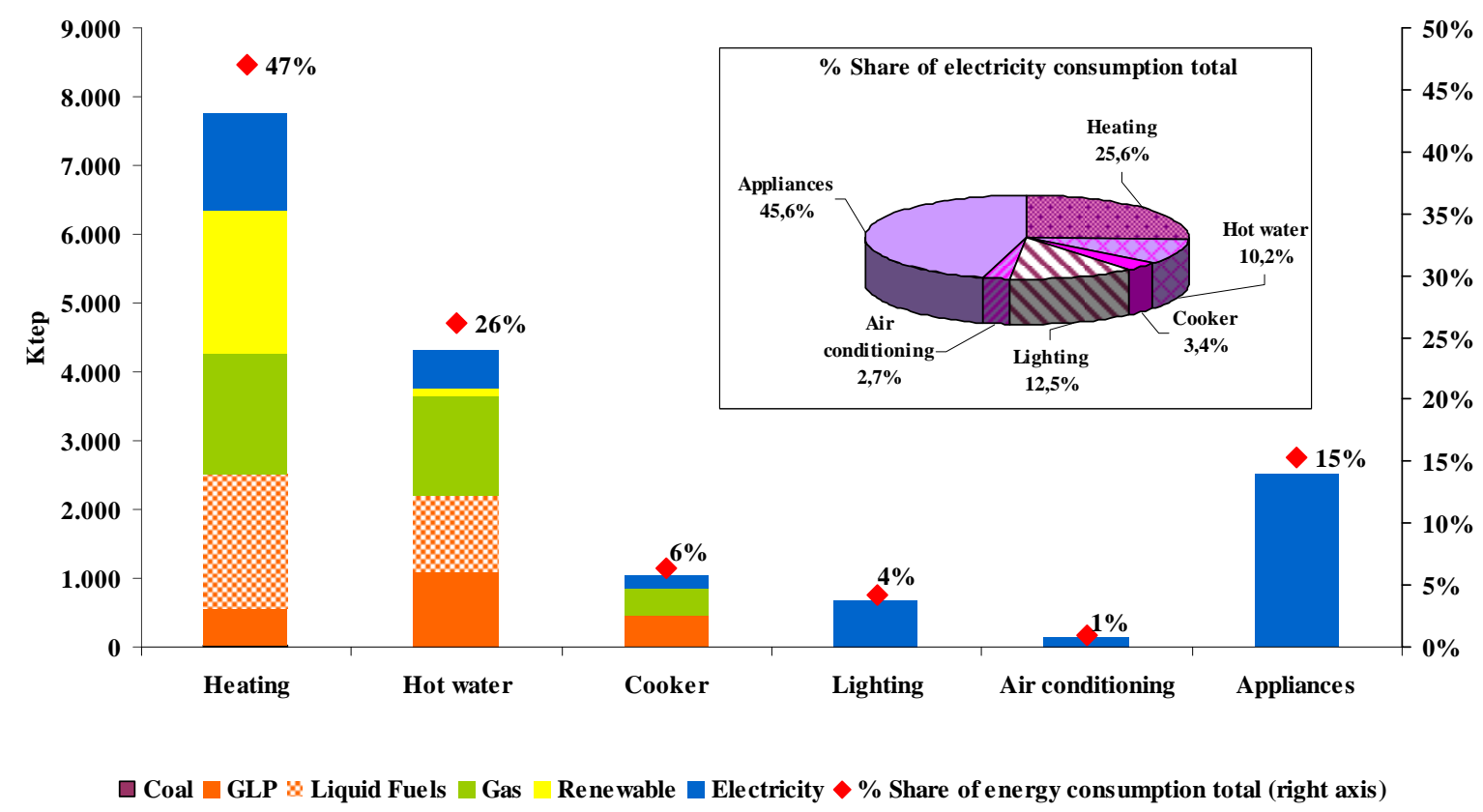

Source: Institute for Energy Diversification and Saving (Instituto para la Diversificación y Ahorro de la Energía (IDAE))

As mentioned in the Introduction, Spanish residential energy demand has grown steadily in recent years, well above other European countries. Two of the main factors explaining this increase are the spectacular increase in population, from 40.5 million inhabitants in 2000 to more than 46 million in 2008 , and an even larger increase of the number of houses (20\% in eight years). As a result of these two simultaneous dynamics, a reduction in the already small average household size was observed during this period across the whole country: from 2.8 persons per household in 2001 to 2.6 in $2008{ }^{2}$ This signifies a convergence with the EU-15 average. The main reason for this increase was the growth of households comprised of only one person ${ }^{3}$, one-parent families and of couples without children. In fact, the increase in the number of houses follows an inverse relation to its size. Obviously, the more individuals living in a household, the higher the electricity consumption is in it. However, the demand shows scale economies so that in aggregate terms the total consumption will be lower. The largest sized households are better equipped to optimize time and common tasks and thus use the equipment more intensely. This effect is clear in hot water or cooker usage. 
Another determinant of the vigorous increase in residential electricity demand has been the economic growth occurring in Spain. From 1993 to 2007, Spain has had the most lasting period of growth in its recent history. This has favoured a prompt convergence between Spanish per capita income and the EU-15 level, up to (in PPP) 88\% in 2010.

All of these socioeconomic advances, along with the progressive similarity in habits and behaviours have allowed for a convergence with the most advanced European countries in terms of household equipment, which in turn has enhanced a faster growth in residential electricity demand in Spain (Table 1). We observe improvements in all kinds of equipment, but one of the most influential changes in the way electricity is consumed in Spain is the increase in the usage of air conditioning systems. Ten years ago, peak demand was reached on the coldest days of winter because of the functioning of electric heating systems, while the summer months did not have much influence on demand. In recent years, peaks have also been reached on the hottest days due to the utilization of air conditioning systems. It is very likely that in coming years peak demands will be reached on summer days instead of in winter.

Table 1. Spanish Household Equipment (Percentage of households)

\begin{tabular}{|c|c|c|}
\hline & 2000 & 2008 \\
\hline With installed heating system (individual and central) & 42.43 & 65.10 \\
\hline With gas heating ${ }^{a}$ & 38.35 & 45.94 \\
\hline With electric heating $^{b}$ & 12.01 & 25.60 \\
\hline Air Conditioning & 15.52 & 35.5 \\
\hline Hot Water & 98.77 & $99.27^{\mathrm{a}}$ \\
\hline Hot water with electricity ${ }^{b}$ & 12.92 & $14.98^{a}$ \\
\hline Independent Dryer & n.d & 21.6 \\
\hline Electric Cooker & 23.13 & $39.61^{\mathrm{a}}$ \\
\hline Dishwasher & 24.56 & 43.50 \\
\hline Freezer & 26.55 & $33.86^{\mathrm{a}}$ \\
\hline Microwave & 54.28 & $78.01^{\mathrm{a}}$ \\
\hline Computer & 30.54 & 59.60 \\
\hline Video & 70.31 & $75.70^{\mathrm{a}}$ \\
\hline Music centre & 59.83 & $64.78^{\mathrm{a}}$ \\
\hline Video games & n.d & 27.70 \\
\hline
\end{tabular}

Of course, together with the former socioeconomic and climate factors, tariffs should be considered as a significant determinant of electricity demand. The Spanish tariff scheme for domestic electricity consumption is a two-part tariff system that is regulated in the majority of cases. This tariff 
is composed of two elements: a fixed monthly charge (or power term), which is based on the level of contracted power, and the (regulated) price per $\mathrm{kWh}$. Since 2007, there have been six levels of power able to be contracted by household consumers in Spain, ranging from 0 to $15 \mathrm{~kW}$. Before that year, only two levels existed. Considering the evolution of the average price of electricity in the residential sector, calculated as the ratio between companies' revenues and their residential customers' electricity consumption $^{4}$, a decrease of $26 \%$ in real terms can be observed from 2000 to 2007 . After the significant increase applied in 2008, this cumulative decrease has been $1.8 \%$. This tendency is the consequence of both an incoherent electricity price policy and an imperfectly designed whole production market. ${ }^{5}$ This combination has led the Government to accumulate a debt with electric companies of 20.000 million Euros (almost 2 points of the Spanish GDP); debt which must be paid via tariffs by current and future consumers. This is the reason why, since 2008 onwards, the tariff increases have been much more severe. ${ }^{6}$ These lower prices make the weight that electricity expenditure has in a standard Spanish family's budget equivalent to $47 \%$ of the weight that it has in an average EU household. This means a small part of family budget: $2.15 \%$ in $2010 .^{7}$

\section{An electricity demand model}

Residential electricity demand can be specified using the basic framework of household production theory (Flaig, 1990; Filippini, 1999; Alberini and Filippini, 2011). According to this theory, households purchase inputs to produce "commodities" that appear as arguments in the household's utility function. In our specific case, a household combines electricity with electrical appliances to produce energy services such as heated rooms, lighting and hot water. In the long-term, the household is employing the optimal level of capital equipment and, therefore, is minimizing the electricity consumption. However, it is interesting to consider that in some cases electricity demand may depart from long-term equilibrium consumption because the stock of electrical appliances cannot easily adjust to this long-term equilibrium. In order to take this potential situation into account, a partial adjustment model has been used. ${ }^{8}$

In line with the description of the electricity sector given in section 2 and the availability of data, we decided to specify the following dynamic model for Spanish residential electricity demand:

$$
\begin{aligned}
\ln E_{i t} & =\beta_{0}+\beta_{E} \ln E_{i t-1}+\beta_{P E} \ln P E_{i t}+\beta_{Y} \ln Y_{i t}+\beta_{P O P} \ln P O P_{i t}+\beta_{H S} \ln H S_{i t} \\
& +\beta_{G A S} G A S_{i t}+\beta_{H D D} \ln H D D_{i t}+\beta_{C D D} \ln C D D_{i t}+\beta_{D T} D T_{t}+\varepsilon_{i t}
\end{aligned}
$$


where $E_{i t}$ is aggregate electricity consumption; $E_{i t-1}$ is the aggregate electricity consumption in period t1; $Y_{i t}$ is real disposable income of the household sector in Euros (Base: 2006=100); $P E_{i t}$ is the real average price of electricity in Euros (Base: $2006=100) ; H S_{i t}$ is household size (total population/number of principal houses); $\mathrm{POP}_{\text {it }}$ is population; $\mathrm{GAS}_{\mathrm{it}}$ is the percentage of households that have access to gas; $H D D_{i t}$ and $C D D_{i t}$ are, respectively, the heating degree days and the cooling degree days all for province $i$ in year $t$; DT is a series of time dummy variables ${ }^{9}$ and, $\varepsilon_{\mathrm{it}}$ is the disturbance term.

Let it be noted that, since electricity consumption and the regressors are in logarithms, the coefficients are directly interpretable as demand elasticities.

\section{Data and the climate variable}

The analysed period covers nine years, from 2000 to 2008, and 47 Spanish provinces. ${ }^{10}$ Table 2 gives some details on the explanatory variables employed in the analysis. To begin with, the choice of the price variable considered in the estimation of equation (1) is not straightforward, because of the two-part tariff structure used in Spain for the residential sector. In this case, two possibilities are available: (i) To use, as suggested by Nordin (1976), the marginal price and detract the fixed fee from the income; and (ii) To use, as suggested by Shin (1985), an average price. This approach has been used recently in several studies. ${ }^{11}$ However, it should be taken into account that the use of an average price could cause an endogeneity problem. In fact, the level of the average electricity price depends both on the amount of electricity consumed and on the level of power contracted. Nevertheless, Shin (1985) argues that, at the aggregate level, the potential for the price to be endogenous with consumption is mitigated by the presence of many different regulated block-pricing levels, in our case many power block-pricing levels. ${ }^{12}$ Recently, this argument has also been also employed by Bernstein and Griffin (2005) and Paul et al. (2009). It should be noted that due to the tariff structure applied in Spain, regional variation of the average electricity price is relatively low. 
Table 2: Definition of variables and descriptive statistics (2000-2008)

\begin{tabular}{|l|c|c|c|}
\hline \multicolumn{1}{|c|}{ Variables } & 1. Quartile & 2. Median & 3. Quartile \\
\hline Electricity consumption (kWh) & $451,834,000$ & $788,745,000$ & $1,384,952,000$ \\
\hline Electricity Price (€/kWh) & 0.081 & 0.101 & 0.111 \\
\hline Disposable Household Income (thousand 2006 €) & $4,126,600$ & $6,744,543$ & $12,300,000$ \\
\hline Population & 356,437 & 580,077 & 955,045 \\
\hline Household size (HS) & 2.633 & 2.732 & 2.856 \\
\hline Gas Penetration (\%) & 0.057 & 0.115 & 0.263 \\
\hline Heating degree days (HDD) 15 & 626 & 969 & 1,486 \\
\hline Heating degree days (HDD) 18 & 1,167 & 1,623 & 2,217 \\
\hline Cooling degree days (CDD) 22 & 59 & 191 & 356 \\
\hline Cooling degree days (CDD) 18 & 311 & 587 & 920 \\
\hline
\end{tabular}

The income variable is measured as the net disposable income available for the sector "households", expressed in real terms. The variable population stands for the total population in each province $i$ in year $t$ : The higher the population of a province the higher the domestic electricity consumption in it. Household size is included in the model to capture the impact of the number of members per household on the demand for electricity. This size has been calculated as the ratio between the population and the number of principal houses and a negative sign is expected for its coefficient.

To account for the impact of natural gas on electricity demand, we introduce the gas penetration rate into equation (1), measured as the number of gas consumers divided by number of houses. Of course, this variable is a proxy for the gas price, which is not available for all provinces. Nonetheless, since the price of natural gas for domestic use in Spain is considerably lower than the price for electricity, we consider that the penetration rate is a fairly accurate proxy. As substitute for electricity, a negative sign of the coefficient is expected. It is noteworthy to point out that this variable may be endogenous, i.e. one could expect an increase of electricity consumption to have a negative impact on the number of households interested in gas consumption. We will consider this possibility below, in the econometric analysis.

There are several methods to measure the effect of climate on electricity demand. One approach is to use the average outside temperature (e.g. Dubin, 1985; Henley and Peirson, 1997; Sailor and Muñoz, 1997). The drawback of this measure is that the non-linear effect of temperature on electricity demand is not reflected. For instance, if the temperature decreases from 20 to 17 degrees Celsius, the level of heating and cooling activities within a house will not change or will do so marginally. This shortcoming is especially acute in Southern European countries, where the nonlinearity is even more marked (Bessec and Fouquau, 2008). 
As an illustration, the annual average values for mean air temperature in Spain vary between values below $2.5^{\circ} \mathrm{C}$ in areas of high altitude (Pyrenees) and of values higher than $17{ }^{\circ} \mathrm{C}$, measured in the provinces of Huelva, Seville and Cadiz. Additionally, average monthly temperature values fluctuate widely throughout the year, with maximum values in the summer (July and August) above $27{ }^{\circ} \mathrm{C}$ in some areas of the Spanish provinces of Caceres, Badajoz, Toledo, Seville, Cordoba and Jaen; and minimum values in winter (December to February) below $0.0^{\circ} \mathrm{C}$ in areas of high altitude. ${ }^{13}$

Another option is the one used by Aroonruengsawat and Auffhammer (2009), who include some dummy variables for climatic zones in their demand model. Although easy and convenient, these dummy variables might also capture other factors. Therefore, they should only be used in special cases. In the case of Spain, the country can roughly be divided into six different climate zones based on temperature (Figure 1): North Coast, North Mediterranean, South Mediterranean, Continental North, Continental South East and Continental South West (Red Eléctrica de España, 1998). ${ }^{14}$ In accordance with this classification, different patterns of domestic electricity consumption are observed (Graph 2). Although an increasing trend is visible across the whole country, in 2008 the coldest zones of the country, the North Coast and Continental North, exhibited the lowest per capita electricity consumption while the hottest areas, the South Mediterranean and Continental South East, presented the highest figures. The most significant increases are observed in the South Mediterranean and North Mediterranean zones. This development could be due to the effect of rapid air conditioning penetration in these regions.

Figure 1. Climate Zones in Spain

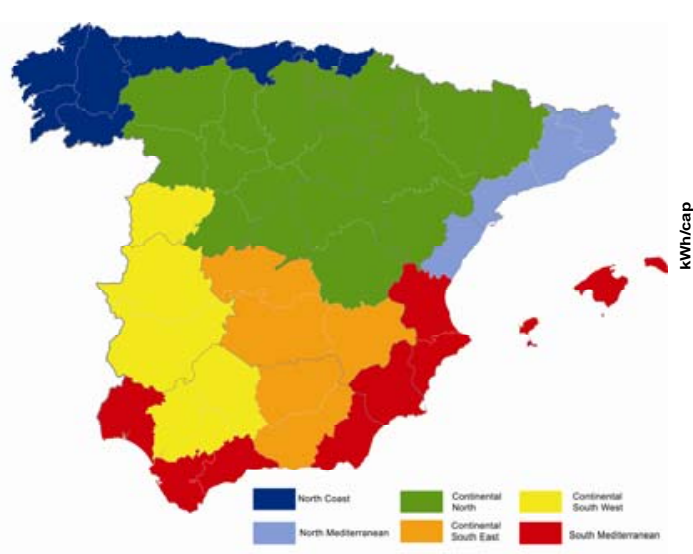

Source: Authors' elaboration with data from REE (1998)
Graph 2. Domestic Electricity consumption per capita in Spain per climate zones

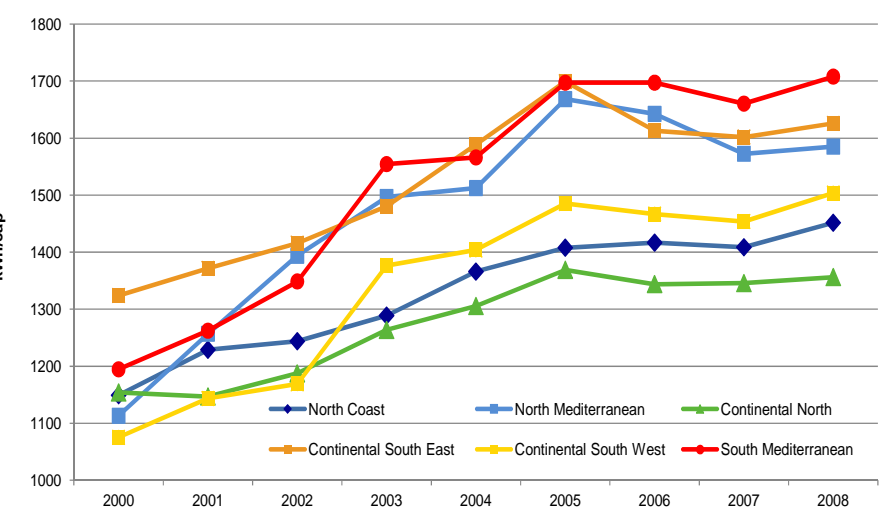

Source: Authors' elaboration 
In order to take into account the non-linear relationship between demand and temperature, most of the existing studies use two climate variables (Table 3), i.e. heating degree days (HDD) and cooling degree days (CDD). Usually, these two measures are defined as follows (Moral-Carcedo and VicénsOtero, 2005):

$$
\begin{aligned}
& \mathrm{HDD}=\sum_{\mathrm{t}=1}^{\mathrm{nd}} \max \left(0 ; \mathrm{T}^{*}-\mathrm{T}_{\mathrm{t}}\right) \\
& \mathrm{CDD}=\sum_{\mathrm{t}=1}^{\mathrm{nd}} \max \left(0 ; \mathrm{T}_{\mathrm{t}}-\mathrm{T}^{*}\right)
\end{aligned}
$$

where $n d$ is the number of days of a particular year, $T^{*}$ is the threshold temperature of cold or heat, and $T_{t}$ the observed temperature on day $t$. HDD and CDD represent the number of days on which the temperature is respectively below and above the predetermined thresholds of cooling and heating, and by how many degrees. The threshold is a "temperature-barrier" over or under which the heating or cooling appliances will be switched on. So, these two variables indirectly measure the demand for heating and cooling services. However, this method has also some drawbacks. There is no unique definition of the values of the "threshold" or comfort temperatures, generally set to $18^{\circ} \mathrm{C}$ (e.g., Pardo et al. 2002; Valor et al. 2001; Alberini and Filippini, 2011). However, such a value might not be appropriate for a country like Spain (Bessec and Fouquau, 2008).

\begin{tabular}{|c|c|c|}
\hline Author & Study Location & Threshold \\
\hline Sailor and Muñoz (1997) & USA & $18.3^{\circ} \mathrm{C}$ except for Florida: $21^{\circ} \mathrm{C}$ \\
\hline Valor et al. (2001) & Spain & $18^{\circ} \mathrm{C}$ \\
\hline Pardo et al. (2002) & Spain & $18^{\circ} \mathrm{C}$ \\
\hline Reiss and White (2005) & California & $\begin{array}{l}\text { HDD: } 60^{\circ} \text { Fahrenheit } \approx 15.56^{\circ} \mathrm{C} \\
\text { CDD: } 70^{\circ} \text { Fahrenheit } \approx 21.11^{\circ} \mathrm{C}\end{array}$ \\
\hline Beccali et al. (2008) & Palermo & $\begin{array}{l}\text { For HDD: } 18.7^{\circ} \mathrm{C} \\
\text { For CDD: } 22^{\circ} \mathrm{C}\end{array}$ \\
\hline Psiloglou et al. (2009) & Athens and London & $\begin{array}{l}\text { Athens: } 20^{\circ} \mathrm{C} \\
\text { London: } 16^{\circ} \mathrm{C}\end{array}$ \\
\hline Eskeland and Mideksa (2010) & Europe & $\begin{array}{l}\text { For HDD: } 18^{\circ} \mathrm{C} \\
\text { For CDD: } 22^{\circ} \mathrm{C}\end{array}$ \\
\hline Labandeira et al. (2011) & Spain & For HDD: $13^{\circ} \mathrm{C}$ \\
\hline
\end{tabular}

Table 3: Literature on electricity demand using the concept of heating and cooling degree days 


\begin{tabular}{|l|l|l|}
\hline & & For CDD: $23^{\circ} \mathrm{C}$ \\
\hline Alberini and Filippini (2011) & USA & $65^{\circ}$ Fahrenheit $\approx 18.33^{\circ} \mathrm{C}$ \\
\hline
\end{tabular}

The usage of two different thresholds for HDD and CDD is also recurrent in literature, with the threshold for HDD staying mainly at $18^{\circ} \mathrm{C}$ and the threshold for CDD set on a higher level (Sailor and Muñoz 1997; Beccali et al. 2008; Eskeland and Mideksa, 2010). Few papers try to use local thresholds other than $18^{\circ} \mathrm{C}$, where the threshold for HDD is normally set lower than $18^{\circ} \mathrm{C}$ and higher than $18^{\circ} \mathrm{C}$ for CDD (Reiss and White, 2005; Psiloglou et al., 2009; Labandeira et al., 2011). The same applies for the Spanish Technical System Operator, which uses $15^{\circ} \mathrm{C}$ as the threshold for HDD and $20^{\circ} \mathrm{C}$ for CDD.

In this sense, Moral-Carcedo and Vicéns-Otero (2005) and Bessec and Fouquau (2008) note that it is more advantageous that the threshold value is estimated rather than being imposed a priori as it allows for a smooth transition from the cold regime to the warm one. This is relevant since there is a neutral zone for mild temperatures where the demand is inelastic to the temperature. In Southern countries like Spain, there is a wide range of temperatures within which electricity appliances related with climate are not affected because they are not used. In particular, Moral-Carcedo and Vicéns-Otero (2005) used non-linear models, including the logistic smooth transition regression (LSTR), threshold regression (TR) and switching regressions (SR) models, to capture the non-linear response of demand to variation in temperature. In the LSTR model they estimate a lower threshold temperature of approximately $15.5^{\circ} \mathrm{C}$. Therefore, $15^{\circ} \mathrm{C}$ seems to be a widely used threshold for HDD alongside the conventional $18^{\circ} \mathrm{C}$.

Following the idea of the LSTR model, which adequately represents the passage from one state in electricity demand (corresponding to cold temperatures) to the other (hot temperatures), with an area of uncertainty in between where neither predominates, we test the threshold value of $18^{\circ} \mathrm{C}$ for the case of Spain for the period between 2000-2008 and reliably define the thresholds needed in order to build the cooling degree days (CDD) and heating degree days (HDD) variables in demand equation (1).

Specifically, we fit the data on temperature and electricity consumption with non-linear functions via a method called iterative non-linear least squares fitting, which minimizes the sum of the squared difference between data points and the function describing the data. ${ }^{15}$ Spanish daily total ${ }^{16}$ electricity demand is plotted against the daily average outside temperature (see Figure 2). The average outside temperature was calculated with a weighted population average of the provincial temperatures.

In our model, the quadratic fitted curve minimum is clearly visible: $17.06^{\circ} \mathrm{C}$. This represents the point of minimal sensitivity in which electricity demand becomes inelastic to temperature change. By 
applying the iterative linear regression method in steps of $0.1^{\circ} \mathrm{C}$ in both directions from $17.06^{\circ} \mathrm{C}$ on in order to estimate a comfort zone, we calculate a comfort zone of between $14.8^{\circ} \mathrm{C}$ and $21.5^{\circ} \mathrm{C} .{ }^{17}$

\section{Figure 2. Response of total daily electricity demand to daily average outside temperature 2000-2008}

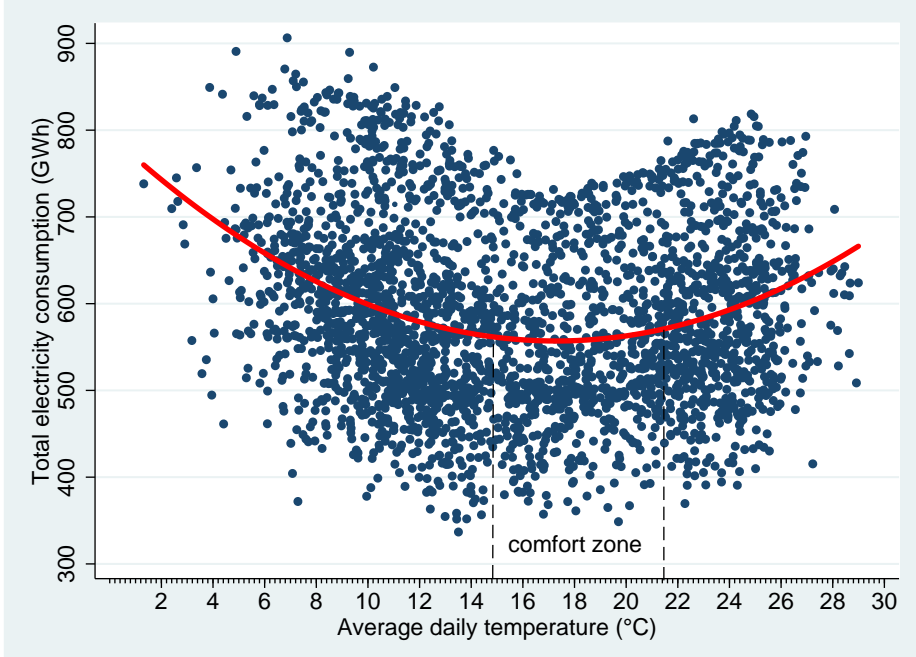

As a result of these disparate approaches, we decided to estimate two types of models: one type with the conventional threshold of $18^{\circ} \mathrm{C}$ and, in addition, a more accurate model with $15^{\circ} \mathrm{C}$ as the threshold for heating and $22^{\circ} \mathrm{C}$ for cooling. The latter model considers the estimated comfort zone between $15-22^{\circ} \mathrm{C}$, in which no heating or cooling will take place. We believe this comfort zone to be much more realistic than a sharp switch from heating to cooling at $18^{\circ} \mathrm{C}$. In our empirical analysis, we expect both coefficients of these climate variables to have a positive impact on electricity demand.

\section{Econometric approach and estimation results}

For the estimation of Spanish domestic electricity demand equations we have an unbalanced panel dataset. To account for unobserved heterogeneity, in panel data analysis we can specify models with either province-specific fixed effects (FE) or with province-specific random effects (RE). However, since the inclusion of a lagged dependent variable in the explanatory variables violates the strict exogeneity assumption, the estimation of the dynamic panel data demand equation (1) using a FE or a RE model is not appropriate. Moreover, as commented in Section 4, the "gas penetration" variable may also be endogenous. In order to verify the endogeneity of this variable we have used the DavidsonMackinnon (1993) test, similar to the (Durbin-Wu-) Hausman test, as well as a $C$ test based on the C 
statistic, which can also be defined as the difference of two Sargan-Hansen statistics. ${ }^{18}$ The result of these tests shows evidence to reject the null hypothesis of exogeneity of the "gas penetration" variable.

Several instrumental variable estimators (IV) have been proposed within the literature to solve the endogeneity problem of the lagged electricity consumption variable. Anderson and Hsiao (1982) proposed a simple instrumental variable estimator. Arellano and Bond (1991) as well as Blundell and Bond (1998) proposed two different estimators based on the general method of moments (GMM-AB and GMM-BB). ${ }^{19}$ The basic idea of the difference GMM-AB estimator is to first-difference the model and then to use lagged levels of the endogenous explanatory variables as instruments. In contrast, the system GMM-BB estimator proposed by Blundell-Bond (1998) estimates the regression in differences together with the regression in levels. For the equation in levels, Blundell-Bond (1998) utilizes lagged first differences as instruments. One general advantage of these GMM estimators is the possibility to consider in a relatively flexible way the presence of more than one endogenous variable, as in our case.

Using the Monte Carlo analysis, Blundell-Bond (1998) show that the GMM-BB estimator seems to be preferable to other IV as well as to the GMM-AB estimators. Among the advantages of the GMM-BB estimator, one of the most significant is the inclusion of the regression in levels, which also takes into consideration the cross-regions variation of the variables. As discussed by Cameron and Trivedi (2005), estimators based on the within variation of the variables such as the fixed effects and the first-differences can produce "very imprecise" coefficients of explanatory variables when the variable's variation over time is dominated by that across regions (between) variation.

Alternatively, Kiviet (1995) suggested an approach to small panel data sets for the estimation of dynamic models based on the correction of the bias of the LSDV model. Judson and Owen (1999) and Kviet (1995) have shown in a Monte Carlo analysis that in aggregate dynamic panels characterized by a $T$ value lower or equal to 20 and an $N$ value lower or equal to 50 , the Anderson-Hsiao and the Kiviet corrected LSDV (LSDVC) estimators are better than the GMM estimator proposed by Arellano and Bond (1991). However, the use of the LSDVC estimator is not appropriate in the presence of more than one endogenous variable. In fact, Kiviet (1995) derives the approximation for the bias of the LSDV estimator when the errors are serially uncorrelated and the regressors are strongly exogenous. As discussed previously, the "gas penetration" variable in the demand equation (1) does not fulfill this condition. Therefore, the LSDVC estimator is not suitable for our empirical analysis. ${ }^{20}$

Considering the aforementioned, for this study we decided to estimate the dynamic demand equation (1) using the two-step system GMM-BB estimator proposed by Blundell and Bond (1998). ${ }^{21}$ Moreover, in order to take into account the endogeneity of the "gas penetration" variable, we estimated 
equation (1) in two alternative specifications. In the first specification-models (1) and (3) - only the endogeneity of the lagged electricity consumption variable is considered. In contrast, in the second specification — models (2) and (4) —we consider both the lagged electricity consumption and "gas penetration" as endogenous. In doing so, in these latter dynamic specifications we combine instrumental variables estimation for one regressor: "gas penetration", within the Blundell-Bond estimation of equation (1).

Furthermore, as previously mentioned, we decided to apply two different definitions for the computation of the HDD and CDD variables. We apply a threshold temperature of 15 degrees Celsius for the computation of the HDD and 22 degrees Celsius for the computation of the CDD (models 1 and 2). Additionally, we use a unique threshold temperature for both HDD and CDD of 18 degrees Celsius (models 3 and 4).

The coefficients of the four versions of the dynamic equation (1) are shown in Table 4 together with the standard errors. We use Windmeijer (2005) finite sample correction of standard errors in order to increase the robustness of the results. Although we expect the coefficients of model (1) and (3) to be biased because of the endogeneity of the "gas penetration" variable, we report them in table 4 for comparison purposes.

The estimates of all of the models are shown together with the $p$-values of the test statistics of serial correlation (AR(1), $\mathrm{AR}(2))$ and the $p$-values of the Sargan and Hansen tests for over-identifying restrictions. The $p$-values of the test statistics for autocorrelation show that in both models the errors exhibit no second order serial correlation. Moreover, the p-values of the Sargan and Hansen test statistics show that in all models the null hypothesis that the instruments as a group are exogenous is not rejected..$^{22}$ Finally, the number of instruments used in the estimation is also presented in Table $4 .{ }^{23}$ 
Table 4. Estimation Results ${ }^{\mathrm{a}, \mathrm{b}}$

\begin{tabular}{|c|c|c|c|c|c|c|c|c|}
\hline & \multicolumn{2}{|c|}{ Model 1} & \multicolumn{2}{|c|}{ Model 2} & \multicolumn{2}{|c|}{ Model 3} & \multicolumn{2}{|c|}{ Model 4} \\
\hline & Coef. & Std. Err. & Coef. & Std. Err. & Coef. & Std. Err. & Coef. & Std. Err. \\
\hline Cons & 0.435 & 1.144 & -0.550 & 0.833 & 0.192 & 1.153 & -0701 & 0.829 \\
\hline Lng $L 1$. & $0.601^{* *}$ & 0.183 & $0.622 * * *$ & 0.117 & $0.601 * * *$ & 0.174 & $0.630 * * *$ & 0.111 \\
\hline Lnp & $-0.082^{* *}$ & 0.032 & $-0.071 * *$ & 0.025 & $-0.082 * *$ & 0.031 & $-0.067 * *$ & 0.024 \\
\hline Lny & $0.183^{*}$ & 0.796 & $0.230^{* *}$ & 0.088 & $0.181^{*}$ & 0.076 & $0.211^{* *}$ & 0.073 \\
\hline Lnpop & 0.253 & 0.164 & $0.203^{*}$ & 0.085 & 0.253 & 0.162 & $0.208^{*}$ & 0.086 \\
\hline Lnhs & -0.248 & 0.167 & $-0.201^{*}$ & 0.083 & -0.251 & 0.166 & $-0.209^{*}$ & 0.087 \\
\hline Lnhdd $_{15}$ & $0.035^{*}$ & 0.016 & $0.061^{*}$ & 0.027 & & & & \\
\hline Lncdd $_{22}$ & 0.011 & 0.006 & $0.012 *$ & 0.005 & & & & \\
\hline $\operatorname{Lnhdd}_{18}$ & & & & & $0.058^{*}$ & 0.027 & $0.088^{*}$ & 0.038 \\
\hline Lncdd $_{18}$ & & & & & 0.026 & 0.015 & $0.031^{* *}$ & 0.012 \\
\hline GAS & $-0.324^{* *}$ & 0.105 & $-0.522 * *$ & 0.191 & $-0.317 * * *$ & 0.092 & $-0.487 * *$ & 0.180 \\
\hline $\mathrm{DT}_{3}$ & $0.063^{*}$ & 0.029 & 0.053 & 0.031 & $0.058^{*}$ & 0.026 & 0.047 & 0.030 \\
\hline $\mathrm{DT}_{4}$ & $0.094 * * *$ & 0.028 & $0.086^{* * *}$ & 0.026 & $0.090^{* * *}$ & 0.025 & $0.080^{* *}$ & 0.026 \\
\hline $\mathrm{DT}_{5}$ & $0.087 *$ & 0.040 & $0.072 *$ & 0.034 & $0.081^{*}$ & 0.036 & 0.067 & 0.035 \\
\hline $\mathrm{DT}_{6}$ & $0.109^{*}$ & 0.043 & $0.087^{*}$ & 0.038 & $0.104 * *$ & 0.039 & $0.083^{*}$ & 0.038 \\
\hline $\boldsymbol{D T}_{7}$ & 0.060 & 0.054 & 0.058 & 0.044 & 0.057 & 0.050 & 0.053 & 0.044 \\
\hline$D_{T_{8}}$ & 0.065 & 0.050 & 0.057 & 0.041 & 0.063 & 0.047 & 0.057 & 0.043 \\
\hline $\mathrm{DT}_{9}$ & $0.112^{*}$ & 0.050 & 0.104* & 0.043 & $0.108^{*}$ & 0.046 & $0.098^{*}$ & 0.042 \\
\hline Sargan test (p-value) & & 0.256 & & 0.640 & & 0.243 & & 0.621 \\
\hline Hansen test (p-value) & & 0.310 & & 0.672 & & 0.294 & & 0.729 \\
\hline Arellano-Bond AR1 test (p-value) & & 0.033 & & 0.022 & & 0.032 & & 0.023 \\
\hline Arellano-Bond AR2 test (p-value) & & 0.870 & & 0.839 & & 0.779 & & 0.779 \\
\hline Number of instruments & & 29 & & 43 & & 29 & & 43 \\
\hline
\end{tabular}

${ }^{a}$ One, two and three stars indicate statistical significance at $10 \%, 5 \%$ and $1 \%$ levels, respectively.

${ }^{\mathrm{b}} \boldsymbol{L n q} \mathbf{L 1}$ is electricity consumption in period $t-1 ; \boldsymbol{y}$ is real disposable income of the household sector; $\boldsymbol{p}$ is the price of electricity; $\boldsymbol{h} s$ is household size; pop is population; $\boldsymbol{G A S}$ is the gas penetration rate; hdd and $\boldsymbol{c d d}$ are, respectively, the heating degree days and the cooling degree days; $\boldsymbol{D T}$ are time dummy variables. 
Most of the parameter estimates are statistically significant and the coefficients generally display the expected signs. The results are satisfactory insofar as the coefficients of the price variables and the coefficient of the lagged variable are significant and carry the expected signs in all models. The coefficient of the lagged variable is used for the computation of the long-run elasticities. The values of the price and income coefficients have the expected signs and are significant in all models. Moreover, the value of these coefficients is relatively similar across all four models. As mentioned previously, the results obtained in model (1) and model (3) could be biased, as in these models only the endogeneity of the lagged electricity consumption variable is taken into account in the econometric estimations. Furthermore, as previously explained, we consider the computation of the HDD and CDD variables using different threshold temperatures more appropriate than the one that considers one unique threshold temperature. For these reasons, the explanation of coefficients and the computation of the short and long-run price and income elasticities will refer specifically to the results obtained in model (2). It is worth mentioning, however, that the results reported in the other models are relatively similar.

In general, the results show that socioeconomic variables such as population and household size, as well as the variables reflecting weather conditions and the penetration of gas, seem to have an important influence on Spanish residential electricity demand.

The estimated coefficient of household size (HS) indicates that the more people living in each house, the less the aggregate electricity demand. The coefficients of the two climate variables, HDD and CDD, show the expected sign and are significant. The estimated heating degree days elasticity is 0.06 . This suggests that a 1 percent increase in the number of heating degree days will (ceteris paribus) result in about a 0.06 percent increase in household electricity consumption. The estimated cooling degree days elasticity is 0.02 . This implies that a 1 percent increase in the number of heating degree days will (ceteris paribus) result in about a 0.02 percent increase in household electricity consumption. Moreover, the comparatively low impact of the CDD could indicate that, in spite of its rapid extension, the penetration or the usage of such air conditioning appliances are still relatively low in Spain. To this respect, it is worth noting that the effects obtained in our models are opposite to those estimated for Spain in Labandeira et al. (2011), who find a higher sensitivity of electricity demand to hot rather than to cold days. The significant and negative sign of the gas penetration rate indicates a clear competition between electricity and gas in the provision of Spanish household energy, particularly in heating and hot 
water systems: every additional percentage point in the gas penetration rate implies a decrease of 0.5 percent in domestic electricity consumption. It is more than likely that natural gas usage will expand in the coming years; therefore one could expect, ceteris paribus, a decrease in household electricity consumption, especially in urban areas. Finally, all time dummy variables show positive coefficients, although only some of them are significant. This result implies that there are some factors affecting the entire Spanish territory and boosting electricity consumption. The most likely explanation is that the housing boom increased during the analyzed period across all Spanish regions. Moreover, these new houses, purchased mainly by young and middle-age owners, have incorporated more and more sophisticated equipment, which has created a dynamic of higher electricity consumption.

Table 5 displays estimates of the short and long-run price and income elasticities. The estimated short-run own price elasticity is approximately 0.07 . This value indicates that residential electricity demand is extremely inelastic. As explained in section 2, Spanish residential prices have been fairly low for the analyzed period and the percentage that electricity expenditure represents in a standard Spanish household's total budget is quite small. As expected, the long-run price elasticity is higher: 0.19 . These numbers are lower than the ones obtained for Spain in Labandeira et al. (2006) and Labandeira et al. (2011). In comparison with other works on different countries, our short-run results are, in general, lower, while the long-run price elasticities are similar to the ones found, for example, in Holtedahl and Jourtz (2004) for Taiwan or Garcia-Cerrutti (2000) for California. Despite the price-inelastic nature of Spanish electricity demand, the long-run results allow us to be moderately optimistic about the effectiveness of future pricing policies to reduce electricity consumption in Spanish households. As long as steady increases of tariffs seem unavoidable in Spain during the coming years (or decades) in order to diminish the bulky tariff deficit, one can expect a long-run positive effect of this policy on electricity demand.

The demand for electricity is responsive to the level of income (Y) with a short-run elasticity of 0.23 and a long-run income elasticity of 0.61 . Since these values are well below unity, income growth apparently results in a less than proportional increase in electricity demand. While these results are again lower than the one found in Labandeira et al. (2006) -they found an elasticity of 0.70 - they are in consonance with other studies, for example, LethPetersen (2002) for Denmark, Hondroyiannis (2004) for Greece or Holtedahl and Joutz (2004) 
for Taiwan. They also suggest that further convergence in per capita income of Spain with the most advanced countries in the EU-15 will not be translated into proportional increases in electrical equipment and in turn into proportional electricity consumption. Nevertheless, the long-run coefficients are high enough to indicate that there is still a certain margin for Spanish households to acquire better equipment as they increase their per capita income.

Table 5. Short-run and long-run elasticities

\begin{tabular}{|c|c|c|}
\hline & \multicolumn{2}{|c|}{ Model $2\left(15^{\circ} \mathrm{C} / 22^{\circ} \mathrm{C}\right)$} \\
\hline & Short-run & Long-run $^{a}$ \\
\hline Price elasticity & -0.07 & -0.19 \\
\hline Income elasticity & 0.23 & 0.61 \\
\hline
\end{tabular}

\section{Concluding Remarks}

In this empirical analysis we have examined the residential demand for electricity in Spain. For this purpose, a dynamic partial adjustment model has been estimated. Aggregate data referring to the period 2000-2008 and 47 Spanish provinces have been used in the estimation.

The paper aims to contribute to the literature on residential electricity demand analysis using aggregate data in two ways. First, by analyzing the impact of weather on electricity demand by using different climate variables for it. For this, special attention has been placed on the method to compute the heating and cooling degree days. Secondly, it aims to provide Spanish policy makers with new values on price and income elasticities based on aggregate panel data.

The empirical results show relatively low short and long-run price elasticities. Therefore, an increase in electricity prices will have a modest impact on the residential electricity demand. Additionally, the relatively high value of the long-run income elasticity would indicate that further increases in per capita income of Spanish households will most likely translate into 
significant, although less than proportional increases in electrical equipment and in turn into higher electricity consumption. Therefore, although improvements in equipment have been substantial in recent years, there is still margin for Spanish households to acquire more and better appliances as they increase their living standards. These two combined factors make it clear that in order to limit the growth rate of electricity consumption policy makers should evaluate the possibility of introducing higher energy efficiency standards for electrical appliances.

Another interesting result is the relative higher sensitivity of electricity demand to cold than to hot days. The relatively low impact of the heating degree days on electricity demand can be explained by the fact that Spanish households are not widely using electric heating systems. On the contrary, gas heating systems are more and more common in Spain. This can explain the relative high impact of gas penetration on electricity consumption. The relatively low impact of the cooling degree days on electricity demand can be explained by the fact that so far only a small fraction of Spanish households are using air conditioning. 


\section{Acknowledgements}

The authors are grateful to the Spanish Ministry of Science and Innovation (ECON2010-21242C03-01) for financial support for the research results reported here. The authors also benefited from comments and support by Fabian Heimsch and two anonymous referees. Naturally, the authors remain solely responsible for any errors or omissions.

\section{References}

Agencia Estatal de Meteorología, 2010. Atlas climático ibérico - Iberian climate atlas. Gobierno de España.

Alberini, A., Filippini, M., 2011. Response of residential electricity demand to price: The effect of measurement error. Energy Economics 33(5), 889-895.

Anderson, T.W., Hsiao, C., 1982. Formulation and estimation of dynamic models using panel data. Journal of Econometrics 18(1), 47-82.

Arellano, M., Bond, S., 1991. Some tests of specification for panel data: Monte Carlo evidence and an application to employment equations. Review of Economic Studies 58(2), 277-97. April.

Arocena, P., Blázquez, L., Grifell-Tatje, E., 2011. Assessing the consequences of restructuring reforms on firms' performance. Journal of Economic Policy Reform 14(1), 21-39.

Aroonruengsawat, A., Auffhammer, M., 2009. Impact of Climate Change on Residential Electricity Consumption: Evidence from Billing Data, California Climate Change Center.

Baltagi, B.H., 2002. Econometric analysis of panel data, New York: John Wiley.

Baum, J. K., Myers, R. A. Kehler, D. Worm, B., Harley, S.J., Doherty, P. A. 2003. Collapse and conservation of shark populations in the Northwest Atlantic. Science 299.

Beccali, M., Cellura, M, Lo Brano, V, Marvuglia, A., 2008. Short-term prediction of household electricity consumption: Assessing weather sensitivity in a Mediterranean area. Renewable and Sustainable Energy Reviews 12(8), 2040-2065.

Berndt, E.R., 1991. The Practice of Econometric, New York: Addison Wesley.

Bernstein, M.A., Griffin, J.M., 2005. Regional differences in the price-elasticity of demand for energy, The Rand Corporation Technical Report.

Bessec, M., Fouquau, J., 2008. The non-linear link between electricity consumption and temperature in Europe: A threshold panel approach. Energy Economics 30(5), 27052721.

Blundell, R., Bond, S., 1998. Initial conditions and moment restrictions in dynamic panel data models. Journal of Econometrics 87(1),115-143

Burney, N.A., 1995. Socioeconomic development and electricity consumption A cross-country analysis using the random coefficient method. Energy Economics 17(3), 185-195.

Cameron, C., Trivedi, P.K., 2005. Microeconometrics: Methods and applications. Cambridge University Press, New York. May 2005.

Cameron, C., Trivedi, P.K., 2009. Microeconometrics using Stata. Stata Press College Station, TX.

CNE (Comisión Nacional de la Energía), 2010. Informe sobre el mercado minorista de electricidad (in Spanish). 
Davidson, R, MacKinnon, J. G., 1993. Estimation and inference in econometrics. Oxford University Press.

Deaton, A., Muellbauer, J., 1980. An almost ideal demand system. The American Economic Review 70(3), 312-326.

Donatos, G.S., Mergos, G.J., 1991. Residential demand for electricity: the case of Greece. Energy Economics 13(1), 41-47.

Dubin, J.A., 1985. Consumer durable choice and the demand for electricity, Amsterdam: NorthHolland.

Eskeland, G.S. \& Mideksa, T.K., 2010. Electricity demand in a changing climate. Mitigation and Adaptation Strategies for Global Change 15, 877-897.

Federico, G., Vives, X., 2008. Competition and regulation in the Spanish gas and electricity markets. Report of the Public-Private Sector Research Center, IESE Business School, University of Navarra.

Filippini, M., 1999. Swiss residential demand for electricity. Applied Economics Letters 6(8), 533-538.

Filippini, M., 2011. Short- and long-run time-of-use price elasticities in Swiss residential electricity demand. Energy Policy 39(10), 5811-5817.

Flaig, G., 1990. Household production and the short-and long-run demand for electricity. Energy Economics 12(2), 116-121.

Garcia-Cerrutti, L.M., 2000. Estimating elasticities of residential energy demand from panel country data using dynamic random variables models with heteroskedastic and correlated error terms. Resource and Energy Economics 22(4), 355-366.

Harris, M., Matyas, S. L., Sevestre, P., 2008. Dynamic models for short panels, in Matyas-Sevestre (eds.). The econometrics of panel data. Third Edition, Darmstadt, Germany: Springer-Verlag, 249-278.

Hayashi, F, 2000. Econometrics. Princeton University Press.

Henley, A., Peirson, J., 1997. Non-Linearities in Electricity Demand and Temperature: Parametric Versus Non-Parametric Methods. Oxford Bulletin of Economics and Statistics 59(1), 149-162.

Holtedahl, P., Joutz, F.L., 2004. Residential electricity demand in Taiwan. Energy Economics $26(2), 201-224$.

Hondroyiannis, G., 2004. Estimating residential demand for electricity in Greece. Energy Economics 26(3) 319-334.

Houthakker, H.S., 1951. Some calculations on electricity consumption in Great Britain. Journal of the Royal Statistical Society. Series A (General) 114(3) 359-371.

Judson, R.A., Owen, A.L. 1999. Estimating dynamic panel data models: A guide for macroeconomists. Economics Letters 65, 9-15.

Kiviet, J.F., 1995. On bias, inconsistency, and efficiency of various estimators in dynamic panel data models. Journal of Econometrics 68(1),53-78.

Labandeira, X., Labeaga Azcona, J., Rodríguez Méndez, M., 2006. A residential energy demand system for Spain. Energy Journal 27, 87-112.

Labandeira, X., Labeaga, J.M., López-Otero, X., 2011. Estimation of Elasticity Price of Electricity with Incomplete Information. Energy Economics 34(3), 627-633.

Lariviere, I., Lafrance, G., 1999. Modelling the electricity consumption of cities: effect of urban density. Energy Economics 21(1), 53-66. 
Leth-Petersen, S., 2002. Micro econometric modelling of household energy use: testing for dependence between demand for electricity and natural gas. The Energy Journal 23(4), 57-84.

Lin, B.Q., 2003. Electricity demand in the People's Republic of China: investment requirement and environmental impact: ERD Working Paper No. 37, Asian Development Bank.

Miller, J., 2002. Modelling residential demand for electricity in the US: a semiparametric panel data approach. Unpublished Manuscript. Department of Economics, Rice University: Texas.

Mohammadi, H., 2009. Electricity prices and fuel costs: Long-run relations and short-run dynamics. Energy Economics 31(3), 503-509.

Moral-Carcedo, J., Vicéns-Otero, J., 2005. Modelling the non-linear response of Spanish electricity demand to temperature variations. Energy Economics 27(3), 477-494.

Narayan, P.K., Smyth, R., Prasad, A., 2007. Electricity consumption in G7 countries: A panel cointegration analysis of residential demand elasticities. Energy Policy 35(9), 4485-4494.

Nickell, S. J., 1981. Biases in dynamic models with fixed effects. Econometrica 49, 1417-1426.

Nordin, J.A., 1976. A proposed modification of Taylor's demand analysis: comment. The Bell Journal of Economics 719-721.

Pardo, A., Meneu, V., Valor, E., 2002. Temperature and seasonality influences on Spanish electricity load. Energy Economics 24(1), 55-70.

Paul, A., Myers, E., Palmer, K., 2009. A Partial Adjustment Model of US Electricity Demand by Region, Season, and Sector. RFF Discussion Paper No. 08-50.

Psiloglou, B. Giannakopoulos, C, Majithia, S., Petrakis, M., 2009. Factors affecting electricity demand in Athens, Greece and London, UK: A comparative assessment. Energy 34(11), $1855-1863$.

Red Eléctrica de España S.A., 1998. Proyecto INDEL - Atlas de la demanda eléctrica española (in Spanish).

Reiss, P.C. \& White, M.W., 2005. Household electricity demand, revisited. Review of Economic Studies 72(3), 853-883.

Sailor, D.J., Muñoz, J.R., 1997. Sensitivity of electricity and natural gas consumption to climate in the U.S.A.-Methodology and results for eight states. Energy 22(10), 987-998.

Shin, J.S., 1985. Perception of price when price information is costly: Evidence from residential electricity demand. The Review of Economics and Statistics 67(4), 591-98.

Silk, J.I., Joutz, F.L., 1997. Short and long run elasticities in US residential electricity demand: A co-integration approach. Energy Economics 19, 493-513.

Valor, E., Meneu, V., Caselles, V., 2001. Daily air temperature and electricity load in Spain. Journal of Applied Meteorology 40, 1413-1421.

von Hirschhausen, C., Andres, M., 2000. Long-term electricity demand in China - From quantitative to qualitative growth? Energy Policy, 28(4), 231-241.

Windmeijer, F., 2005. A finite sample correction for the variance of linear efficient two-step GMM estimators. Journal of Econometrics 126(1), 25-51. 


\section{Appendix}

\section{Table A1. Data Sources}

\begin{tabular}{|c|c|c|}
\hline Variable & Description & Source \\
\hline Electricty Consumption (Mwh) & Number of Mwh consumed by residential consumers $(<15 \mathrm{KW})$ & $\begin{array}{l}\text { Ministry of Industry, Tourism and Trade } \\
\text { (MITYC) }\end{array}$ \\
\hline $\begin{array}{l}\text { Real Average Price of Electricity } 2006 \\
\text { (thousand } € / \text { kwh) }\end{array}$ & $\begin{array}{l}\text { Companies' revenues from electricity consumed in the residential } \\
\text { sector / Electricity consumption in residential sector }\end{array}$ & Own calculation with data from MITYC \\
\hline $\begin{array}{l}\text { Households' Real Disposable Income (2006 } \\
\text { thousand } € \text { ) }\end{array}$ & Real disposable income of the institutional sector: Households & $\begin{array}{l}\text { National Institute of Statistics (Instituto } \\
\text { Nacional de Estadística (INE)). Regional } \\
\text { Accounts }\end{array}$ \\
\hline Total Population & Total population in each province & $\begin{array}{l}\text { INE. Active Population Survey. (Encuesta } \\
\text { de Población Activa) (EPA)) }\end{array}$ \\
\hline Number of houses (Total) & Number of houses there are in each province & Ministry of Economy and Finance \\
\hline Number of principal houses & Number of houses there are in each province & Ministry of Economy and Finance \\
\hline Household size & Population / principal houses & $\begin{array}{l}\text { Own calculation with data from INE and } \\
\text { Ministry of Economy and Finance }\end{array}$ \\
\hline HDD 18 & Heating Degree Days with threshold of $18^{\circ} \mathrm{C}$ & $\begin{array}{l}\text { Own calculation with data from Spanish } \\
\text { Meteorology Agency (Agencia Española } \\
\text { de Meteorología (AEM)) }\end{array}$ \\
\hline CDD 18 & Cooling Degree Days with threshold of $18^{\circ} \mathrm{C}$ & Own calculation from AEM data \\
\hline HDD 15 & Heating Degree Days with threshold of $15^{\circ} \mathrm{C}$ & Own calculation from AEM data \\
\hline CDD 22 & Cooling Degree Days with threshold of $22.2^{\circ} \mathrm{C}$ & Own calculation from AEM data \\
\hline Gas penetration rate & Number of gas consumers divided by number of houses & $\begin{array}{l}\text { Own calculation with data from MICYT } \\
\text { and Ministry of Economy and Finance }\end{array}$ \\
\hline
\end{tabular}




\section{NOTES}

${ }^{1}$ Note that in 2008 the residential electricity consumption was 73 million MWh, which means a share as large as $27.4 \%$ of total Spanish electricity demand.

${ }^{2}$ This size is calculated considering only principal houses. National Institute of Statistics in Spain (INE) defines "household" as the group of people that commonly occupies a family principal house or part of it and consume and/or share food or other goods and housekeeping.

${ }^{3}$ The number of households with only one person grew $100 \%$ from 2000 to 2010 due mainly to the growth of people younger than 65 years who decided to live alone $(193 \%)$ and also the ageing of population in Spain. The number of households with two persons grew 53\% (data of the Household Budget Continuous Survey (Encuesta Continua de Presupuestos Familiares (ECPF)) and Household Budget Survey (Encuesta de Presupuestos Familiares (EPF)).

${ }^{4}$ Unfortunately, the data provided by Spanish authorities does not allow isolating the domestic segment's revenues; therefore the average price is calculated by the residential sector, including the commercial segment. In spite of this shortcoming, this average price could be considered as a good proxy to domestic tariffs variation.

${ }^{5}$ See Arocena et al. (2011) for an analysis of the effects of Electricity Sector Law on the stakeholders of the electricity sector.

${ }^{6}$ One of the most damaging effects of the tariff deficit is that it is slowing down the effective liberalization of the residential segment and the transition toward a non-regulated price regime. Since 2003 all consumers have had access to the liberalized market and contract their consumptions at market price. And since 2009 the regulated tariff system has been reduced to the so-called last resort tariff for low-tension consumers. However, as long as incumbents offer regulated tariffs lower than market prices, the potential incoming companies are not able to compete: they face negative margins (Federico and Vives, 2008). As a result, in 2010, 85\% of households were still consuming electricity at regulated prices. A side effect of this scenario is that the prices offered by retailers in the free market are indeed more related to regulated tariffs than to whole market prices (CNE, 2010).

${ }^{7}$ According to the Household Budget Survey. Expressed in 2006 prices.

${ }^{8}$ A Partial Adjustment Model assumes that the change in log actual demand between any two periods is only some fraction of the difference between the logarithm of actual demand in period $t-1$ and the logarithm of the long-run equilibrium demand in period $t$. For a discussion of this type of model in the estimation of electricity demand see Berndt (1991), Alberini and Filippini (2011) and Filippini (2011).

${ }^{9}$ These time dummy variables try to control the impact of time-varying factors that affect all provinces at the same time such as technological change, household behavioural changes, or general climate change.

${ }^{10}$ See Appendix for a detailed description of variables and data sources.

${ }^{11}$ See Bernstein and Griffin (2005), Paul et al. (2009) and Alberini and Filippini (2011).

${ }^{12}$ At this point, it is worth remembering that in $2010,85 \%$ of domestic consumers in Spain were still in the regulated market.

${ }^{13}$ This explanation is based on data from the Spanish Meteorology Agency (Agencia Estatal de Meteorología).

${ }^{14}$ These six homogeneous zones were defined by applying a cluster technique to a daily temperatures historical (time) series of 44 Spanish observatories.

${ }^{15}$ Therefore, although this process uses the same goal as described for linear regression, it differs from it in that it is an iterative or cyclical process. This involves making an initial estimate of the parameter values based on prior experience of the data and then producing the fitted curve for the current set of coefficients. The first iteration implies computing the sum of squares based on the initial parameter values. The second iteration involves changing the parameter values by a small amount or step and recalculating the sum of squares. The direction and magnitude of the adjustment depend on the fitting algorithm. This process is repeated several times to ensure that changes in the parameter values result in the smallest possible value of sum of squares or any other specified convergence criteria. Several different algorithms can be used in non-linear regression. We have chosen the quadratic algorithm, which extrapolates the minimum (or maximum) of a quadratic fitted to the function at its current point.

${ }^{16}$ Note that the consistency of the results would improve by using the daily pairs \{temperature, consumption associated to each province instead of aggregated data at a national level. Unfortunately, daily data on residential consumption at the province level was not available. Not even total electricity demand (the sum of all sectors) is available at the province level.

${ }^{17}$ This means that we lay a linear regression from $17.06^{\circ} \mathrm{C}$ on each side $\left(\mathrm{y}=\beta_{0}+\beta_{1} \cdot \mathrm{x}\right)$, where $y$ is the consumption and $x$ is the daily temperature). As soon as the slope $\left(\beta_{1}\right)$ was significant (at the $5 \%$ level), the iteration stops and we assume the temperature to have an influence on electricity demand from this point on. 
${ }^{18}$ For a discussion of these tests see Hayashi (2000) and Baum et al. (2003).

${ }^{19}$ Baltagi (2002) contains a discussion on this issue and a presentation of econometric models for panel data.

${ }^{20}$ In a preliminary analysis we also estimated the demand equation (1) using the LSDVC econometric approach. However, the results obtained were not completely satisfactory, i.e. several coefficients were not significant. As pointed out above, the relatively low number of statistically significant explanatory variables could be explained by the low within variation of these variables. Moreover, the fact that the "gas penetration" variable is endogenous also creates some estimation problems.

${ }^{21}$ In the preliminary analysis, we also estimated the demand equation (1) using the conventional FE and the OLS model. This procedure will give us the possibility to verify the consistency of the results obtained with the BBGMM. In fact, it is well known that the coefficient of the lagged variable in OLS is upwardly biased whereas in FE model is biased downwards. Therefore, the results of the coefficient of the lagged variable obtained using the BBGMM should lay between the two. The results obtained in this preliminary analysis confirmed this expectation. For a discussion on this issue see Nickell (1981) and Harris et al. (2008).

${ }^{22}$ Further, the null hypothesis that the lagged differences of the explanatory variables are not correlated with the residuals has been verified using the difference-Hansen test. We could not reject this null hypothesis in all models at a level of significance of $10 \%$. This result supports the choice of the system BB-GMM estimator.

${ }^{23}$ With a relatively small $N$, it is important to keep the number of instruments less than or equal to the number of groups (or cross-sectional units, which in our case are the 47 regions) to improve efficiency and prevent the Sargan/Hansen tests from becoming weak. See Cameron and Trivedi (2009) for a discussion of this issue. 